\title{
A satellite-based crop-factor hydrological model for broad-scale estimates of irrigated area, crop-water- requirement and crop phenology
}

\author{
$\underline{\text { A. L. Weeks }}^{a}$, C. Beverly ${ }^{a}$ and J. McInnes ${ }^{a}$ \\ a Agriculture Victoria, Department of Economic Development, Jobs, Transport and Resources \\ Email:anna.weeks@ecodev.vic.gov.au
}

\begin{abstract}
Analysis of satellite derived data to estimate plant performance and crop water requirement (CWR: the minimum water required to maintain crop growth in stress-free conditions) has been used extensively across Victoria. The most commonly applied approach assumes that for a well-watered crop, evapotranspiration can be estimated as the product of a crop factor and a reference potential evapotranspiration. The crop factor is approximated as a linear function of satellite-based Normalised Difference Vegetation Index (NDVI) and the reference potential evapotranspiration is derived from meteorological data. CWR is simply the summed evapotranspiration minus the rainfall over a defined period.
\end{abstract}

This approach has been shown to be reasonable for specific crop-types within irrigation districts when validated against water supply information, however there remains significant limitations. These include: (1) the methodology only applies to well-watered areas; (2) the application assumes pre-existing knowledge of the location of irrigated land parcels and the duration of irrigation cycles; (3) there is no consideration of stored water in the soil profile at the start of the growing season nor soil drainage characteristics throughout the year; and (4) often satellite data is only processed once during the peak summer period and extrapolated over an assumed irrigation period. These limitations can significantly impact the robustness and precision of the calculations of CWR.

To overcome these constraints the technique outlined in this paper explicitly links satellite derived crop factors with a daily hydrological water-balance model that accounts for rainfall exfiltration, water distribution through a soil profile, surface runoff, subsurface lateral flow, deep drainage and recharge. The approach uses daily interpolated NDVI data, derived from Landsat-8 satellite images (2013-present) captured at 16 day intervals across Victoria and pre-processed to remove cloud and cloud shadow. Crop factors are derived as a function of NDVI from which potential transpiration is estimated. Actual transpiration is based on potential evapotranspiration, root architecture and available water stored in the soil profile. In this study an irrigation event is triggered when the difference between potential and actual transpiration exceeds a threshold amount. During irrigation events, applied irrigation matches transpiration deficit such that transpiration is not limited by available soil water in the root zone. The major advantage of incorporating a hydrological water-balance model is that soil water dynamics impact on transpiration estimates from which irrigation events are triggered. Additionally, time varying NDVI estimates define quantifiable crop factors which when incorporated into a daily water balance model enhances the accuracy of model predictions. This improves on the previous approach whereby irrigation events are simply defined by the difference between rainfall and evapotranspiration over a predefined period.

In this study the linked approach is evaluated by comparing historical survey and irrigation water delivery information with predicted estimates of irrigated area and CWR. Results demonstrate that the integration of satellite imagery data with a biophysical water balance model is capable of estimating CWR in irrigated regions within benchmark survey limits and with a median percentage error of less than $12 \%$ relative to water-use licence data. An important advantage of this approach is that it requires no pre-existing knowledge of land use and can be applied consistently across irrigated and non-irrigated areas alike. With the widespread availability and low cost of satellite data this approach raises the possibility of predicting crop water requirement globally or aggregated to any spatial scale greater than the pixel resolution of satellite imagery.

Keywords: Irrigated horticulture water use, satellite data, crop water requirement 
Weeks et al., A satellite-based crop-factor hydrological model for broad-scale estimates of irrigated area, crop-water-requirement and crop phenology

\section{INTRODUCTION}

In the last decade under the Murray Darling Basin Plan, Northern Victoria has seen surface sustainable diversion limits for irrigated agriculture drop by over $500 \mathrm{GL}$ to $3371 \mathrm{GL} / \mathrm{yr}$. This, combined with the expansion of water trade and changing market drivers has led to significant disruption to traditional irrigated industries. The Victorian Water Policy Model (WPM; Agriculture Victoria, 2016) was designed to model whole-of-farm response to changes in water availability, and, at a broader scale, inform government on the economic impacts of water availability and trade between different irrigation regions (Figure 1). To support the farm-scale production models that underpin the WPM, detailed, historic information on irrigated areas and water application is required so that trends in water use across irrigation regions can be assessed. Such datasets are not generally available across broad areas for multiple industries over time. This paper describes a process of capturing this information by utilising freely available, high-resolution satellite imagery.

Published methods of estimating CWR are generally based on the crop-factor $(K c)$ approach described in Allen et al. (1998) where evapotranspiration of a well-watered crop is defined as the product of a crop-factor and a reference potential evaporation (PET). Studies by Tasumi (2005) and Whitfield (2012) have further shown that crop-factors can be reliably estimated as a linear function of a satellite-derived NDVI.

$$
C W R=\sum_{t=a}^{b} E T_{t}-R_{t}, \quad E T_{t}=K c * P E T_{t}, \quad K c=f n(N D V I)
$$

Here $E T(t)$ is the estimated evapotranspiration, $R(t)$ the daily rainfall and $K c$ a static crop-factor defined over the irrigation period from $t=[a, b]$. Whilst this approach has been shown to provide robust estimates of irrigation it cannot be used as a predictive tool to flag irrigated areas as the method only applies to wellwatered areas and requires pre-existing knowledge of irrigation parcels and growing season. Previous work (Weeks et al., 2015) highlighted the value of utilising interpolated daily NDVI data to identify periods of irrigation. This enabled the automated estimation of CWR and showed some potential as a tool to flag irrigated areas. Further development of this concept found that for this approach to be successful, knowledge of available soil water was critical so that irrigation events were not falsely flagged. This has led to the development of the linked approach described below.

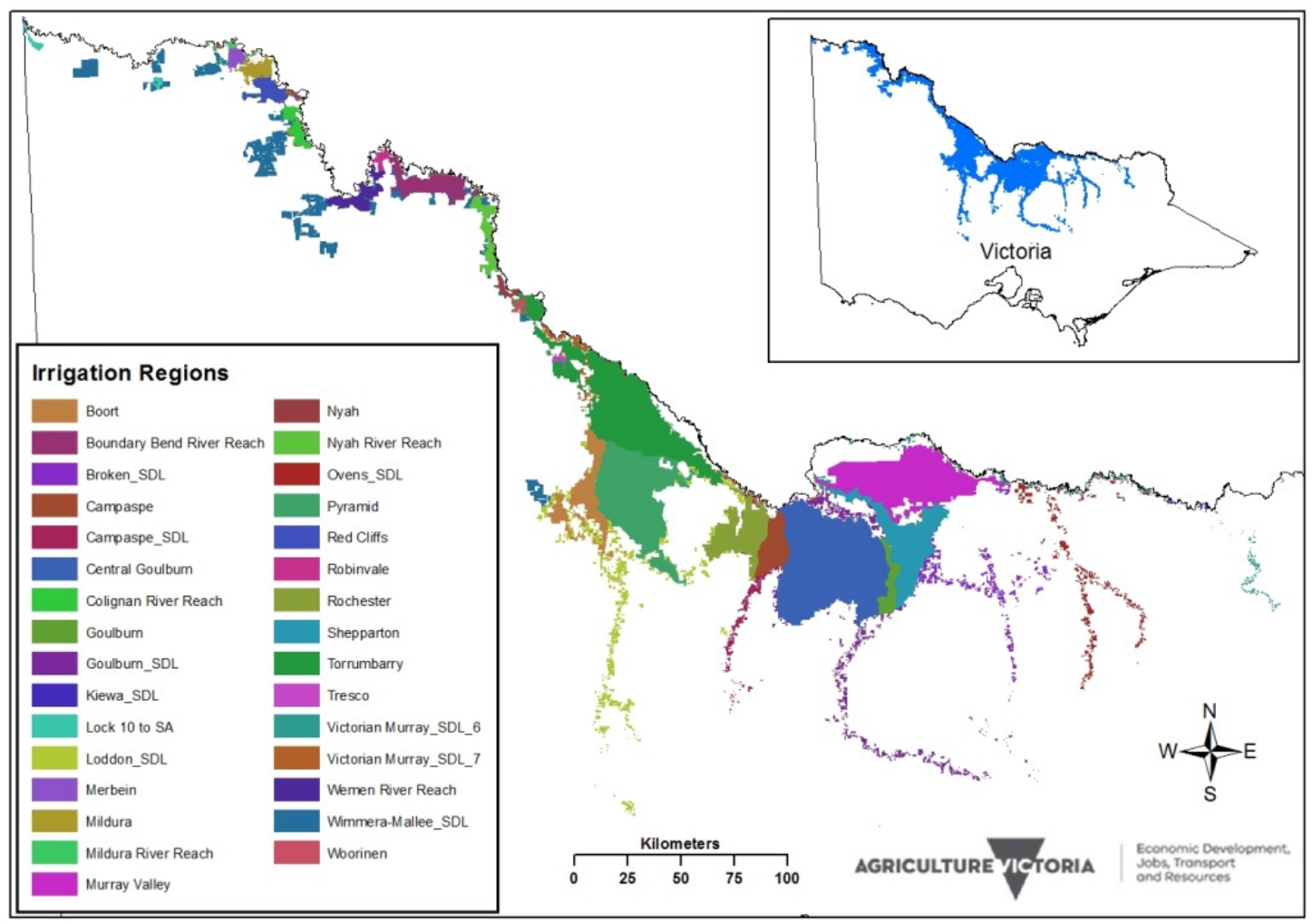

Figure 1. Modelled irrigation regions for Northern Victoria used for the Victorian Water Policy Model

\section{METHODS}

The linked approach is designed to identify irrigated areas and derive estimates of water application and water balance. The basic components are described below and include: (1) time-varying satellite-derived 
Weeks et al., A satellite-based crop-factor hydrological model for broad-scale estimates of irrigated area, crop-water-requirement and crop phenology

NDVI and associated crop-factors; (2) a biophysical water balance model; and (3) links whereby the timevarying crop factors are incorporated into the biophysical model from which predictions of irrigation and water balance estimates are derived.

\subsection{Satellite-derived NDVI crop-factors}

All satellite data was captured and pre-processed based on Weeks et al. (2015). The application utilises downloads from the USGS Landsat- 8 satellite for the period from mid-2013 to present. The domain spans the State of Victoria, capturing data from over twenty Landsat-8 'scenes' (approximately $180 \mathrm{~km} \mathrm{x} 185 \mathrm{~km}$ ) at a $30 \mathrm{~m}$ resolution every sixteen days with data filtered to remove cloud and cloud cover, reprojected and resampled to a master grid and stored in a binary datacube format. Pixel-scale NDVI data was interpolated to a daily trace using the MATLAB shape-preserving Piecewise Cubic Hermite Interpolating Polynomial (PCHIP) which was found to be more robust for regions of sparse NDVI data then a cubic spline approach used in Weeks et al., 2015.

Crop factors are often approximated by a linear function of NDVI (Tasumi et al., 2005 and Whitfield et al., 2012) and are reported as reliable estimates within known irrigated parcels. This relationship cannot be applied to dryland areas as evapotranspiration (ET) is overestimated and well-exceeds available rainfall. The linked approach overcomes this by limiting ET to available soil water, only irrigating when crop factors remain high over a period of significant soil water deficit. Even when accounting for limited ET, erroneous irrigation flags can occur, particularly in areas of native scrubland and trees which typically have a high, flat NDVI trace over time. To more robustly delineate irrigated from dryland areas, a dynamic crop-factor relationship was trialled, where crop-factor Kc was estimated as a function of NDVI minus a baseline factor, calculated from the lowest decile of NDVI data for the irrigation year (July- June) as defined in equation (2):

$$
K c=f n(N D V I)=1.46 * N D V I-\text { baseline }(N D V I) / 2
$$

\subsection{Water balance model}

The water balance model has been based on the Catchment Analysis Tool CAT1D model (Beverly, et al., 2005; Weeks et al., 2008; Beverly, 2009), a biophysical model that simulates the plant-soil-water dynamics in an agricultural system. The model (Figure 2) runs on a daily time-step with inputs including daily rainfall and potential evaporation (Mpot) sourced from the SILO $0.05^{\circ}$ gridded Data Drill Jeffrey et al., 2001, (https://www.longpaddock.qld.gov.au/silo/datadrill/) along with slope and soils data. Soils are characterised by the number and soil profiles, the volumetric water content $(\mathrm{mm})$ of each profile at air-dry (adry), wilting point $(w p)$, field capacity $(f c)$ and saturation (sat), and the saturated hydraulic conductivity $(K S a t)$ of soil profile layers in $\mathrm{mm} / \mathrm{day}$. Infiltration into the soil profile is calculated as a function of rainfall, crop-cover, slope and saturated hydraulic conductivity with excess attributed to runoff. Water is redistributed through the soil profile based on a linear cascading bucket model where the capacity of each bucket is the equivalent of the saturated water content (sat) of each soil horizon. Soil evaporation occurs from the top two soil profiles and is based on Ritchie's two-stage evaporation algorithm (Ritchie, 1972). After infiltration, StageI drying occurs up to a specified limit $\left(S I_{\text {Limit }}\right)$ at a potential rate which is calculated as a function of cover and potential evaporation. StageII drying then continues to occur up to the adry limit due to diffusive evaporative processes that are related to the slope of the drying curve (CONA) and the number of days since rain $(d s r)$.

Potential transpiration (POT) is estimated using the NDVI crop factors ( $K c$ defined above) then distributed across the soil profiles based on a root density function $(D F A C)$. Actual transpiration $(T)$ is calculated in a two-step process. First, a water-limited transpiration $(T w l)$ is calculated based on the plant available water above wilting point or a defined rooting limit $r L i m=f c_{3}\left(1-\frac{d_{r}}{d_{3}}\right)$, where, assuming only three soil layers, $f c_{3}$ is the field capacity of soil layer $3, d_{3}$ is the depth of soil layer 3 , and $d_{r}$ is the maximum rooting depth of the vegetation. Second, a transpiration deficit Kc ratio $(T D e f K c)$ is calculated. If $T D e f K c$ exceeds a threshold value it is assumed that irrigation has occurred and transpiration occurs at the potential rate, otherwise transpiration occurs at the water-limited rate. After transpiration is accounted for, excess water above field capacity $(f c)$ is transferred to the lower soil profile at a rate limited by the saturated hydraulic conductivity of the layer (KSat). Any further excess water above saturated capacity (sat) is assigned to lateral subsurface flows (LatFlow). Soil water is updated at each time-step to account for gains from infiltration and irrigation and losses through soil evaporation, transpiration, lateral flow, and infiltration to the lower soil profile. In the final step, irrigation, transpiration, soil evaporation and soil water are summed over all soil profiles, recharge is estimated as the water transferred through the lowest soil profile and lateral flows are summed and combined with the runoff term. 
Weeks et al., A satellite-based crop-factor hydrological model for broad-scale estimates of irrigated area, crop-water-requirement and crop phenology

\subsection{Linking NDVI crop factors with water balance model}

The linked approach can be applied broadly across the whole landscape, both dryland and irrigated. Satellitederived NDVI crop-factors defines daily potential transpiration (POT) which, in in combination with soil water estimates as predicted using the water balance model, defines actual transpiration (Twl). Irrigation is triggered when the crop factor multiplied by the transpiration deficit ratio $\left(K c *\left(1-\frac{T w l}{P O T}\right)\right)$ exceeds a threshold value. The likelihood of an irrigation event decreases when soil water is not limiting and actual transpiration approaches potential. When soil water is limiting $(T w l \rightarrow 0)$, irrigation is triggered when the crop-factor $K c$ exceeds a threshold value of 0.3 . This threshold value is about the level at which plants become photosynthetically active (NDVI $=0.4$, Nemani and Running, 1997). This approach explicitly links the NDVI crop factors with transpiration estimates, irrigation events and applied irrigation application predicted using the a biophysical water balance model.

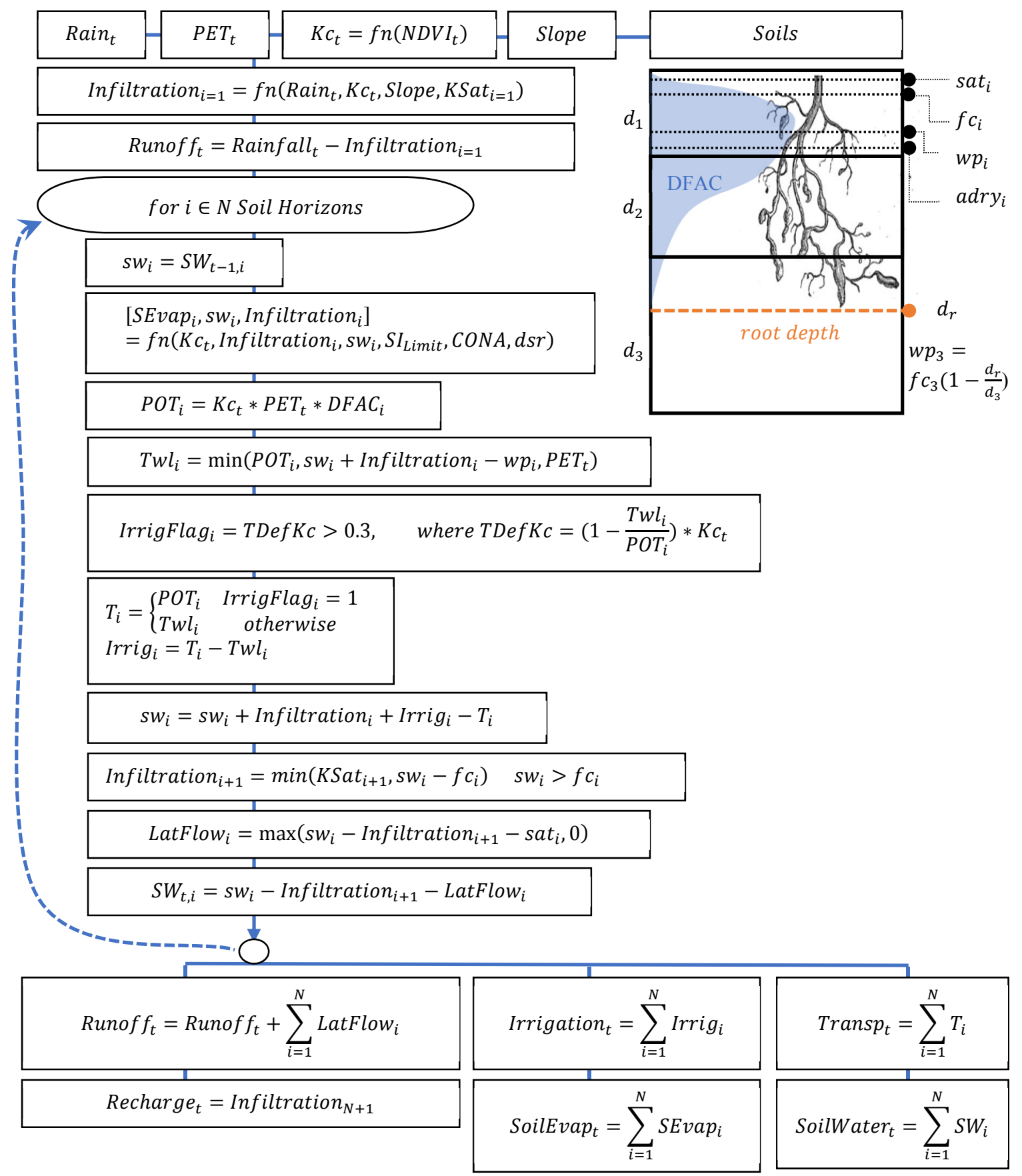

Figure 2. Overview of the links between NDVI derived crop-factors and the water balance model. 
Weeks et al., A satellite-based crop-factor hydrological model for broad-scale estimates of irrigated area, crop-water-requirement and crop phenology

\section{RESULTS AND DISCUSSION}

The daily NDVI crop-factor enforced water balance model was run across the Northern irrigation regions of Victoria with results amalgamated over irrigation seasons (July ${ }_{Y} \rightarrow$ June $_{Y+1}$ ) for the period 2013-2016. Modelled annual pixel-scale results included; irrigated water application, irrigation area, runoff, soil evaporation, transpiration, change in soil water and recharge. Across the Northern irrigation zones, limited data was available across successive irrigation seasons to confirm modelled estimates of irrigation area and water use. Results reported in this paper have been compared with: (1) the 2014 irrigation season water-uselicense information; (2) mapping supplied water to parcel boundaries (DELWP,2016); and (3) detailed 2014 horticultural land-use sourced from SunRISE (http://www.sunrise21.org.au/) that classifies irrigated paddocks by horticultural crop type. There is some complexity in dealing with the water-use-license information as there can be multiple licenses attributed to differing, overlapping land parcels within a single season and, in some cases, supplied water is utilised outside the boundaries of the mapped land parcel. Figure 3 presents a comparison of the total modelled water diversion to licensed water use for the 2014 irrigation season across selected irrigation regions of Northern Victoria. In this analysis modelled irrigation has been summed over the licensed parcel boundaries and compared to total water supplied for each irrigation region. Results suggest reasonable correlation between total modelled and licensed water diversion with $50 \%$ of regions showing differences of less than $2 \mathrm{GL}$ and $80 \%$ with less than $10 \mathrm{GL}$ and a median percentage error of less than $12 \%$ relative to water-use licence data.

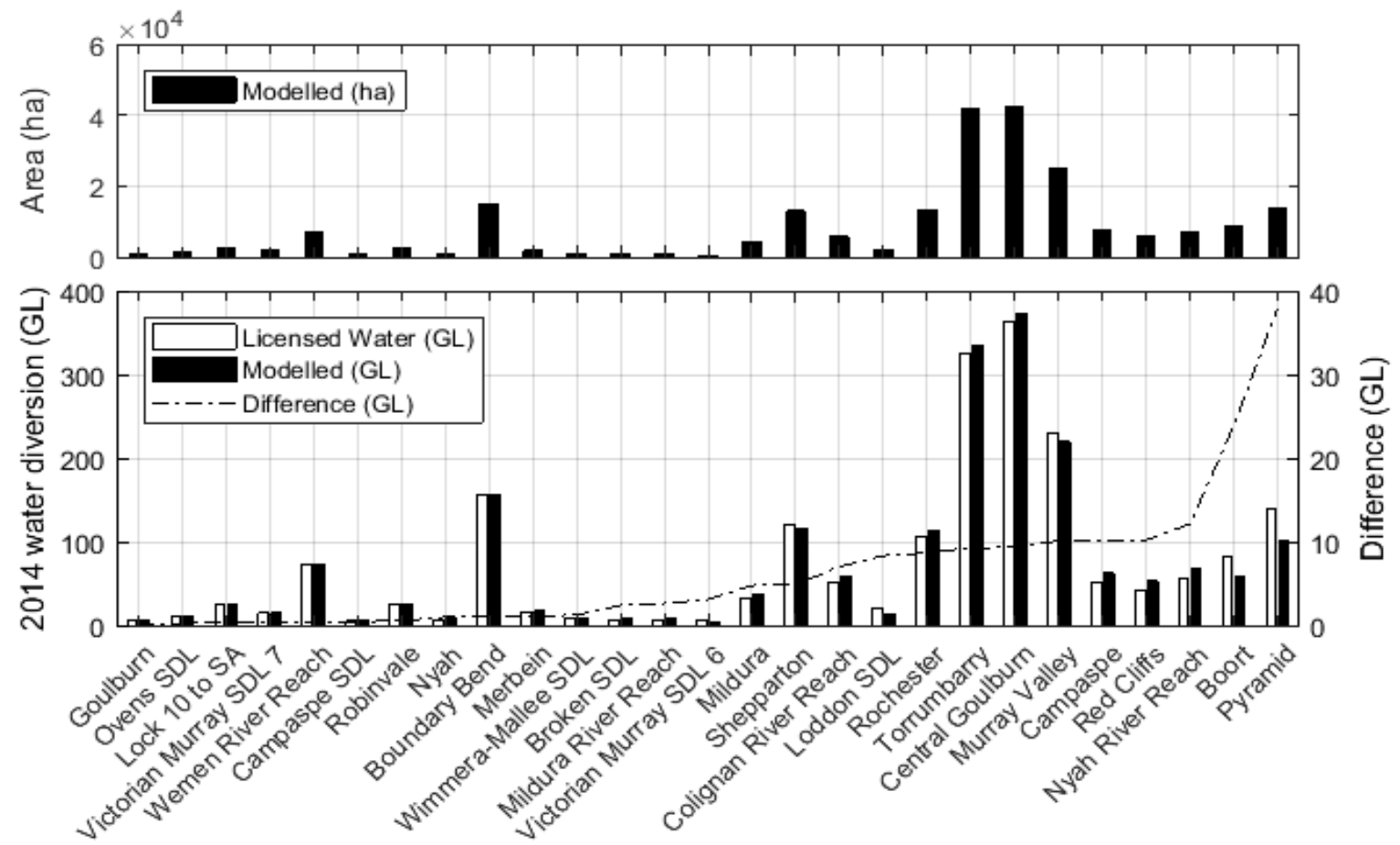

Figure 3. Comparison of total modelled water diversion to licensed water use for the 2014 irrigation season across selected irrigation regions of Northern Victoria.

The difference between modelled and licensed water can generally either be attributed to: (1) ambiguity in the water-license boundary information; (2) inability of the linked model to detect and flag an irrigation event; and (3) crop-specific errors in estimation of water-use attributed to conceptual limitations in the NDVI crop-factor approach. Interactive tools have been developed to explore these issues, utilising the detailed SunRISE land use information to assess model performance across different horticultural crop types. As an example, Figure 4 presents the modelled, 2014 CWR for the Boundary Bend irrigation zone, with areas identified as almond (SunRISE) outlined in black. The linked model correctly flags all almond parcels as irrigated, showing good correlation between the SunRISE parcel areas and flagged irrigation areas $\left(R^{2}=\right.$ 0.97, Figure 4(b)). To consider licensed water-use by crop type, each water license has been distributed across all pixels flagged as irrigated within the license boundary, weighted by the modelled CWR. Figure 4(c) shows the comparison of this pixel-scale water-use license data to modelled CWR for almond pixels $\left(R^{2}=0.36\right)$. The low $R^{2}$ reflects the complexity of assigning water use information to land parcels, varying irrigation delivery technologies, and possible use of alternative water source including farm dams and groundwater. Figure 4(d) shows the distribution of CWR over the almond growing area for successive 
(a)

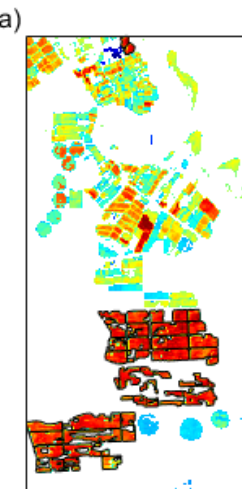

Irrigated Crop Water Requirement 2014

(d)

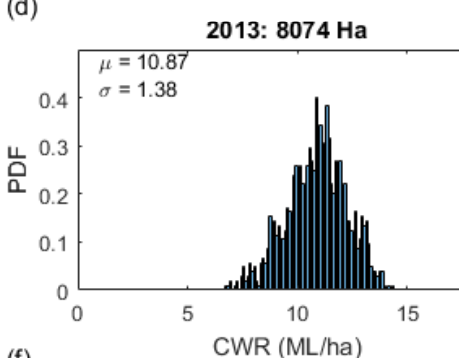

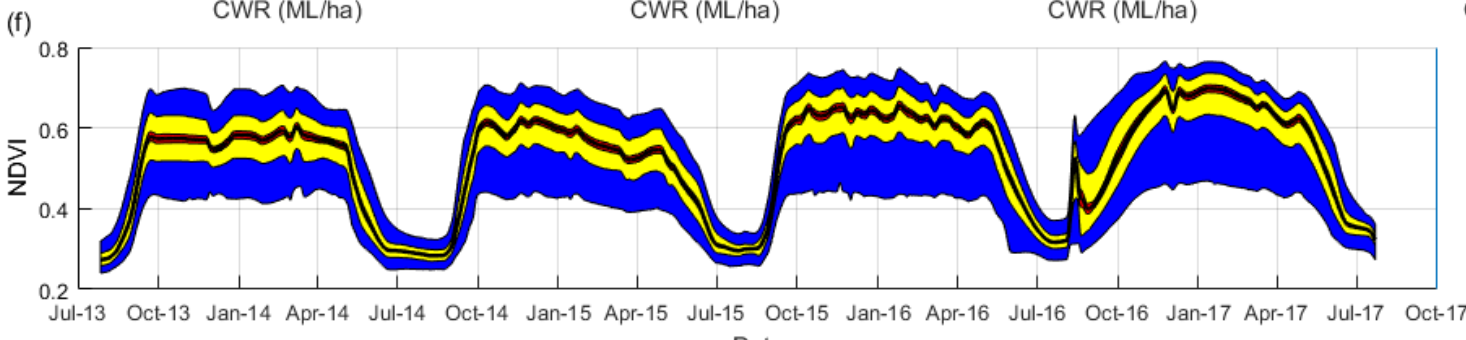

2015: $8460 \mathrm{Ha}$

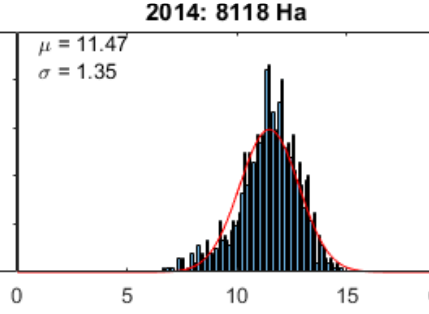

(b)

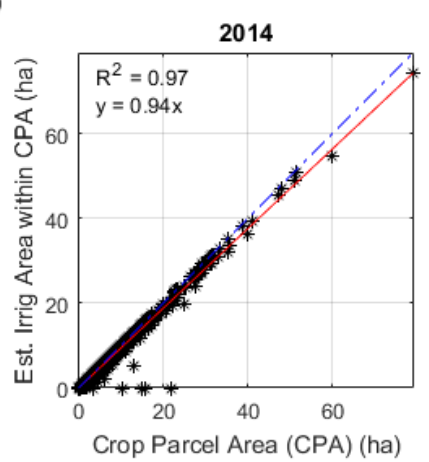

2016: $8404 \mathrm{Ha}$

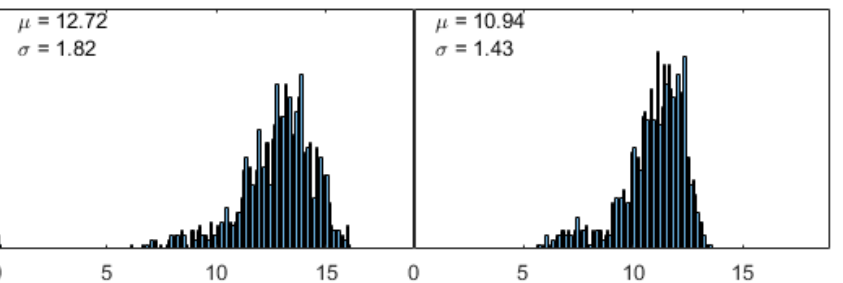

CWR (ML/ha) (c)

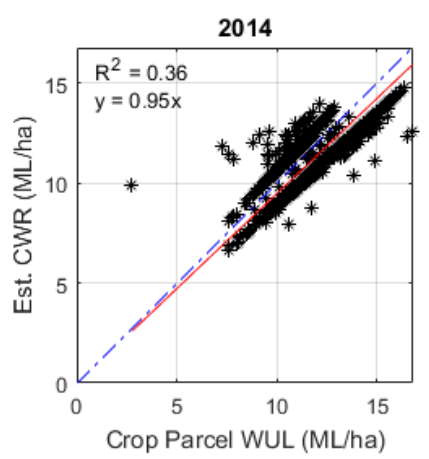

(e)

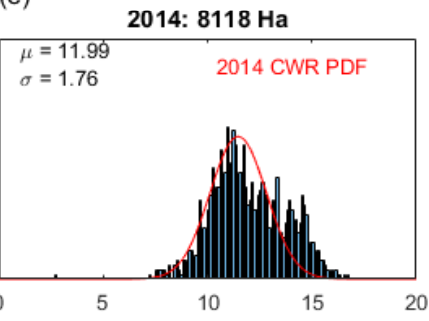

(g)

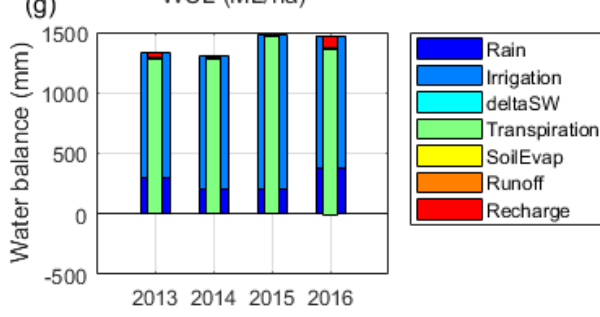

Figure 4. 2014 Irrigated crop water requirement for almonds in the Boundary Bend River Reach Irrigation zone. Figure 4(b). SunRISE parcel areas vs. flagged irrigation area. Figure 4(c). Distributed water use license (ML/ha) vs. modelled CWR (ML/ha). Figure 4(d). Probability distribution function (PDF) of modelled CWR (ML/ha) from 2013-2016. Figure 4(e). Comparison of 2014 licensed water-use (PDF) to normal distribution of 2014 CWR PDF. Figure 4(f). Distribution of interpolated NDVI. Figure 4(g). Annualised components of the water balance model for the almond growing areas of the Boundary Bend irrigation region. 
irrigation seasons. Mean values range between 10.7ML/ha and 12.7 ML/ha, well within reported almond irrigation median benchmark values of $9.7 \mathrm{ML} / \mathrm{ha}$ to $15 \mathrm{ML} / \mathrm{ha}$ for years 2003 to 2011 (DPI, 2012). A comparison of the distributed water-use-license data $(\mu=11.99)$ and the modelled CWR $(\mu=11.47)$ is presented in Figure 4(e). Figure 4(f) shows the distribution of interpolated NDVI over time, with a median value in the summer months of approximately 0.6, dropping below 0.3 over winter. Figure $4(\mathrm{~g})$ shows the annualised components of the water balance model for the almond growing areas of the Boundary Bend irrigation region, illustrating the inter-annual rainfall variability and subsequent impact on irrigation application. There is an ongoing body of work which is using the validation methods presented in Figure 4 to assess the robustness of the linked model over differing horticultural crop types.

\section{CONCLUSION}

The developed framework linking satellite derived crop factors to a biophysical water balance model has significant advantages to traditional simple crop water deficit approaches. These include quantifiable daily NDVI and crop factors that can be used to identify crop phenology, irrigated area and applied irrigation. Importantly, the time-varying crop-factors indirectly account for crop management at the land management scale as required for biophysical models, but which is not usually available across the scales afforded by satellite data. This provides more transparent and robust district scale predictive modelling. Results suggest that the developed approach reliably identifies irrigated area and reasonably predicts irrigation water use.

\section{REFERENCES}

Agriculture Victoria (2016). Northern Victoria Water Policy Model. Model Documentation 2016.

Allen, R.G., Pereira, L.S., Raes, D., and M. Smith (1998). Crop evapotranspiration: Guidelines for computing crop water requirements, FAO Irrigation and Drainage Paper 56, FAO, Rome.

Beverly, C., 2009. Models of the Catchment Analysis Tool (CAT1D Version 32), August 2009, Technical Reference Manual (ed. C. Beverly), Department of Primary Industries, Victoria.

Beverly, C., Bari, M., Christy, B., Hocking, M., Smettem, K., 2005. Predicted salinity impacts from land use change: a comparison between rapid assessment approaches and a detailed modelling framework. Australian Journal of Experimental Agriculture 45, 1453-1469

DPI (2012). Almond Irrigation Benchmarking 2002-2011. Horticulture Services. Department of Primary Industries. ISBN 978-1-74326-153-8.

Jeffrey, S.J., Carter, J.O., Moodie, K.B. and Beswick, A.R. (2001). Using spatial interpolation to construct a comprehensive archive of Australian climate data. Environmental Modelling and Software, Vol 16/4, pp 309-330. DOI: 10.1016/S1364-8152(01)00008-1.

Nemani, R., and S. Running (1997). Land Cover Characterization using multi-temporal RED, NEAR-IR and Thermal-IR data from NOAA/AVHRR. Ecological Applications, 7, 79-90. http://dx.doi.org/10.1890/1051-0761(1997)007[0079:LCCUMR]2.0.CO;2

Richie, J.T. (1972). A model for predicting evaporation from a row crop with incomplete cover. Water Resources Research, 8, 1204-1213.

Tasumi, M., Allen, R.G., Trezza, R., and J.L. Wright (2005). Satellite-Based Energy Balance to assess within-population variance of crop coefficient curves, Journal of Irrigation and Drainage Engineering ASCE, 131, 94-109.

Weeks A., Beverly C., Whitfield D., and M. Abuzar and J. McInnes (2015). Automated satellite-based estimation of crop water requirement for irrigated horticultural industries in northern Victoria. 21st International Congress on Modelling and Simulation, Gold Coast, Australia, 29 Nov to 4 Dec 2015 www.mssanz.org.au/modsim 2015

Weeks A., Christy B., Lowell K. and C. Beverly (2008). The catchment analysis tool: demonstrating the benefits of interconnected biophysical models. In Landscape Analysis and Visualisation: Spatial Models for Natural Resource Management and Planning, Pettit C, Cartwright W, Bishop I, Lowell K, Pullar D, Duncan D (eds). Springer: Berlin; 49-72.

Whitfield, D., O’Connell, M., McAllister, A., McClymont, L., Abuzar, M., and Sheffield, K. (2012). SEBAL-METRIC estimates of crop water requirement in horticultural crops grown in SE Australia, Acta Horticulturae, 922, 141-148. 